\title{
Article
}

\section{Intracellular mechanisms underlying the nicotinic enhancement of LTP in the rat dentate gyrus}

Welsby, Philip J., Rowan, Michael J. and Anwyl, Roger

Available at http://clok.uclan.ac.uk/5923/

Welsby, Philip J. ORCID: 0000-0002-2110-8198, Rowan, Michael J. and Anwyl, Roger (2009) Intracellular mechanisms underlying the nicotinic enhancement of LTP in the rat dentate gyrus. European Journal of Neuroscience, 29 (1). pp. 65-75. ISSN 0953816X

It is advisable to refer to the publisher's version if you intend to cite from the work. http://dx.doi.org/10.1111/j.1460-9568.2008.06562.x

For more information about UCLan's research in this area go to http://www.uclan.ac.uk/researchgroups/ and search for < name of research Group>.

For information about Research generally at UCLan please go to http://www.uclan.ac.uk/research/

All outputs in CLoK are protected by Intellectual Property Rights law, including Copyright law. Copyright, IPR and Moral Rights for the works on this site are retained by the individual authors and/or other copyright owners. Terms and conditions for use of this material are defined in the policies page.

\section{CLoK}

Central Lancashire online Knowledge www.clok.uclan.ac.uk

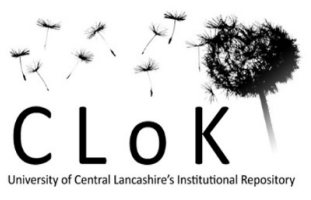


Intracellular mechanisms underlying the Nicotinic Enhancement of LTP in the Rat Dentate Gyrus

Philip Welsby ${ }^{3}$, Michael Rowan ${ }^{2}$ and Roger Anwyl ${ }^{1}$

Department of Physiology ${ }^{1}$ and Pharmacology and Therapeutics ${ }^{2}$, Trinity College, Dublin 2, Ireland and Department of Pharmacology and Therapeutics, NUI Galway, Ireland $^{3}$

Name of corresponding author:

Dr Philip Welsby, Department of Pharmacology and Therapeutics, NUI Galway, Galway, Ireland.

Tel: 35391493826

Fax: 35391525700

E-mail: philip.welsby@nuigalway.ie

Enquiries to ranwyl@tcd.ie or philip.welsby@nuigalway.ie

Keywords: kinase, allosteric modulator, synaptic plasticity, acetylcholinesterase Running Title: Intracellular mechanisms of Nicotinic Enhanced LTP

No of text pages: 31

No of figures: 6

No of tables \& equations: n/a

No of words in whole manuscript: 7726

No of words in abstract: 243

No of words in introduction: 582 


\section{Abstract}

We have previously shown that activation of nicotinic acetylcholine receptors enhanced long-term potentiation (LTP) in the rat dentate gyrus in vitro via activation of $\alpha 7$ nicotinic acetylcholine receptor (nAChR). In the present studies, mechanisms underlying the acute and chronic nicotinic enhancement of LTP were examined. In particular, the involvement of activation of intracellular kinases was examined using selective kinase antagonists, and the effects of enhancing cholinergic function with a positive allosteric modulators of the $\alpha 7 \mathrm{nAChR}$ and with acetylcholine inhibitors was also investigated. Activation of extracellular signal-regulated kinase (ERK) and cAMPdependent protein kinase (PKA) was found to be involved in the induction of the acute nicotinic enhancement of LTP although not control LTP. In contrast, activation of the tyrosine kinase Src, $\mathrm{Ca}^{2+}$-calmodulin-dependent protein kinase II, Janus kinase 2 and p38 mitogen-activated protein kinase were not involved in the acute nicotinic enhancement of LTP although Src activation was necessary for control LTP. Moreover, activation of phosphoinositide 3-kinase was involved in the acute nicotinic enhancement of LTP to a much lesser extent than in control LTP. Chronic nicotine enhancement of LTP was found to be dependent on PKA, ERK and Src kinases. Acute nicotinic enhancement of LTP was occluded of chronic nicotine treatment. The positive allosteric modulator PNU-120596 was found to strongly reduce the threshold for nicotinic enhancement of LTP, an affect mediated via the $\alpha 7 \mathrm{nAChR}$ as it was blocked by the selective antagonist methyllycaconitine. The acetylcholinesterase inhibitors tacrine and physostigmine enhanced control LTP. 


\section{Introduction}

Cholinergic innervation of the hippocampus modulates electrical activity and other processes that contribute to learning and memory (Decker and McGaugh, 1991; Jones et al, 1999; Levin, 2002). This includes modulation of activity dependent synaptic plasticity such as LTP which is the most convincing model of learning and memory (Bliss and Collingridge, 1993; Bear and Malenka, 1994). Loss of high affinity nicotinic receptors and cholinergic neurons is associated with neurodegenerative disorders such as Alzheimer's disease (AD), Parkinson's disease and Lewy body dementia (Whitehouse et al, 1982; Arendt et al, 1995). Current therapeutic approaches in the treatment of $\mathrm{AD}$ utilise $\mathrm{AChE}$ inhibition and positive allosteric modulation of cholinergic signalling. Other positive allosteric modulators have been described including ivermectin (Krause et al, 1998), 5-hydroxyindole (Zwart et al, 2002) and more recently PNU-120596 (Hurst et al, 2005).

Neuronal nicotinic receptors are located in both the central and peripheral nervous systems and are members of the superfamily of ligand gated ion channels. Nine alpha ( $\alpha 2-10)$ and three beta subunits ( $\beta 2-4)$ have been identified in the CNS (Picciotto et al, 2001), each having unique expression profiles. Within the hippocampus, the single most abundant nicotinic acetylcholine receptor (nAChR) is the homomeric $\alpha 7$ subtype (Seguela et al, 1993; Dominguez del Toro et al, 1994; Le Novere and Changeux, 1995). It has a pentameric structure forming a channel with high calcium permeability and has consistently been demonstrated to enhance synaptic transmission associated with an increase in intracellular calcium and transmitter release (Gray et al, 1996; Radcliffe and Dani, 1998; Ji et al, 2001; Sharma and Vijayaraghavan, 2003). Nicotine was found to

enhance LTP of excitatory postsynaptic potentials (EPSPs) in the dentate gyrus (Welsby et al, 2006, 2007) and to convert weak stimuli evoked short-term potentiation into LTP in the CA1 (Fujii et al, 1999; Ji et al, 2001; Mann and Greenfield, 2003). The selective 
$\alpha 7$ nAChR agonists choline and 2, 4-dimethoxybenzlidine anabaseine have also been found to mimic the facilitative action of nicotine on LTP (Matsuyama et al, 2000; Hunter et al, 1994).

Stimulation of nAChRs can activate a variety of kinase pathways. Nicotine activation of $\alpha 7$ nAChRs in SH-SY5Y cells and cultured hippocampal neurones leads to PKA and subsequently ERK1/2 activation (Dajas-Bailador et al, 2002). In primary cultures of rat cortical neurons the neuroprotective effects of acetylcholinesterase inhibitors are mediated by $\alpha 7$ and $\alpha 4 \beta 2$ receptor activation of JAK2 and PI3K (Shaw et al, 2002; Takada-Takatori et al, 2006). In CA1 interneurons $\mathrm{GABA}_{\mathrm{A}}$ receptors are reversibly inhibited following calcium influx via postsynaptic $\alpha 7$ nAChRs and subsequent CaMKII and p38 MAPK activation (Zhang and Berg, 2007). nAChRs themselves are kinase regulated as preventing tyrosine phosphorylation of $\alpha 7$ nAChR's results in increased acetylcholine evoked currents and $\alpha 7$ nAChR cell surface expression (Cho et al, 2005; Charpantier et al, 2005).

Previously, we described an in vitro model where acute or chronic nicotine treatment results in nicotinic enhancement of LTP in hippocampal slices. However, little is known about the mechanisms underlying such nicotinic enhancement. In the present study, we investigated the kinase involvement and effects of AChE inhibitors and positive allosteric modulators on the nicotinic enhanced LTP in the dentate gyrus. We found that acute $\alpha 7 \mathrm{nAChR}$ stimulated enhancement of high frequency stimulation (HFS) induced LTP required activation of ERK and PKA while chronic nicotine enhancement of LTP was dependent on PKA, ERK and Src kinases. Moreover, LTP could be enhanced in the absence of nicotine by the AChE inhibitors physostigmine and tacrine and the positive allosteric modulator PNU-120596 reduced the threshold for LTP induction. 


\section{Materials and Methods}

All experiments were carried out on transverse slices of the rat hippocampus (Wistar males, age 3-4 weeks, weight 40-80 g). Animal use was approved by the Bioresources Committee, Trinity College Dublin, and licensed by the Department of Health and Children, Ireland, in accordance with European Communities Council Directive (86/609/EEC) and were designed in such a way as to minimize the number of animals used and their suffering. The brains were rapidly removed after decapitation and placed in cold oxygenated $\left(95 \% \mathrm{O}_{2} / 5 \% \mathrm{CO}_{2}\right)$ media. Slices were cut at a thickness of $350 \mu \mathrm{m}$ using an Intracell Plus 1000 and placed in a storage container containing oxygenated medium at room temperature $\left(20-22^{\circ} \mathrm{C}\right)$ for $1 \mathrm{hr}$. The slices were then transferred to a recording chamber for submerged slices and continuously superfused at a rate of $5-6 \mathrm{ml} / \mathrm{min}$ at $30-32^{\circ} \mathrm{C}$. The control media contained: (mM) NaCl, $120 ; \mathrm{KCl} 2.5$, $\mathrm{NaH}_{2} \mathrm{P04}$, 1.25; $\mathrm{NaHCO}_{3}$ 26; $\mathrm{MgS0}_{4}, 2.0$; $\mathrm{CaCl}_{2}$, 2.0; D-glucose 10. All solutions contained $100 \mu \mathrm{M}$ picrotoxin (Sigma) to block GABAA-mediated activity.

Drugs used were from Sigma unless otherwise stated; (-)-Nicotine, U0126, H-89, Rp-8-CPT-cAMPs, wortmannin, genistein, SU-6656, KN-62, tyrphostin AG-490, SB203580, MLA, physostigmine, tacrine, PP2 (Calbiochem) and PNU-120596 (Tocris). In chronic studies, nicotine $(1 \mathrm{mg} / \mathrm{kg}$ ), its vehicle (sterile $0.9 \% \mathrm{NaCl}$ ), PNU-120596 $(1 \mathrm{mg} / \mathrm{kg})$ and its vehicle (5\% DMSO and 5\% Solutol in PBS) was administered to male

rats (age 3-4 weeks, weight 40-80 g) twice daily by subcutaneous injection for 14 days prior to in vitro slice preparation as described above.

Standard electrophysiological techniques were used to record field potentials. Presynaptic stimulation was applied to the medial perforant pathway of the dentate gyrus using a bipolar insulated tungsten wire electrode, and field EPSPs were recorded at a control test frequency of $0.033 \mathrm{~Hz}$ from the middle one-third of the molecular layer 
of the dentate gyrus with a glass microelectrode. The inner blade of the dentate gyrus was used in all studies. In each experiment, an input-output curve (afferent stimulus intensity versus EPSP amplitude) was plotted at the test frequency. For all experiments, the amplitude of the test EPSP was adjusted to one-third of maximum ( 1.0 mV). LTP was evoked by HFS consisting of 8 trains, each of 8 stimuli at $200 \mathrm{~Hz}$, intertrain interval 2s, with the stimulation voltage increased during the HFS so as to elicit an initial EPSP of the train of double the normal test EPSP amplitude. Measurements of LTP are given at 60 min post-HFS. Recordings were analysed using p-CLAMP (Axon Instruments, CA, USA). Values are the means \pm S.E.M. for n slices. Two-tailed Student's t-test was used for statistical comparison.

\section{Results}

\section{ERK and PKA are required for the acute nicotinic enhancement of LTP but not control LTP}

In the medial perforant pathway of the dentate gyrus HFS induced control LTP measuring 154 $\pm 8 \%, \mathrm{n}=7$ (60 min post HFS) (Fig. 1A). As in our previous studies, perfusion of nicotine $(5 \mu \mathrm{M})$ for ten minutes prior to HFS significantly enhanced the induction of control LTP, which measured 187 $\pm 9 \%(\mathrm{p}<0.05 ; \mathrm{n}=6 ; 60$ min post HFS) (Fig. 1A).

U0126 is a selective inhibitor of both the active and inactive forms of MAP kinase kinase (MEK1/2), the immediate upstream activator of ERK1/2, and has been previously shown to inhibit ERK1/2 activation in acute slices (Roberson et al, 1999;

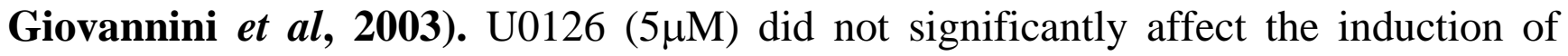
control LTP $(139 \pm 9 \%, \mathrm{p}>0.1 ; \mathrm{n}=7)$ but completely prevented the induction of the nicotinic enhancement of LTP, which was not significantly different from control in the

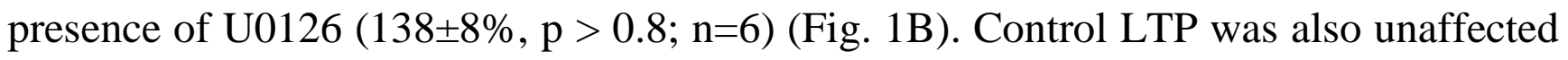


by PKA inhibition. Thus induction of LTP was not blocked by effective concentrations of the PKA inhibitor H-89 ( $2 \mu \mathrm{M})$ (Yang et al, 2008) (147 $\pm 3 \%, \mathrm{p}>0.9$; $\mathrm{n}=7$ ) (Fig. 1C) or the non hydrolysable cAMP analogue Rp-8-CPT-cAMPS $(150 \pm 5 \%, p>0.8 ; n=7)$ $(100 \mu \mathrm{M})$ (Fig. 1D). However, both H-89 and Rp-8-CPT-cAMPs completely inhibited nicotinic enhancement of LTP, with LTP induction in the presence of either H-89 or Rp-8-CPT-cAMPs plus nicotine not significantly different from control LTP $(144 \pm 7 \%$, $\mathrm{p}>0.5 ; \mathrm{n}=9$ and $145 \pm 5 \%, \mathrm{p}>0.8 ; \mathrm{n}=6$ respectively) (Fig. 1C, $\mathrm{D}$ ).

Thus nicotinic-enhanced LTP, unlike control LTP, is dependent on activation of ERK and PKA.

Src is required for control LTP but not acute nicotinic enhancement of LTP, while PI3K is involved in acute nicotinic-enhancement of LTP to a lesser extent than in control LTP.

The isoflavone genistein is a potent competitive inhibitor of tyrosine kinase phosphorylation, both receptor and non-receptor mediated (Kawakami et al, 2001). As in previously published studies (Casey et al, 2002; Huang and Hsu 1999; O’Dell et al, 1991) control HFS induced LTP was strongly inhibited in the presence of genistein $(10 \mu \mathrm{M})$ with LTP not being significantly different from baseline $(113 \pm 12 \%, \mathrm{p}>0.6$; $\mathrm{n}=11$ ) (Fig. 2A). In contrast, substantial LTP was induced in the presence of nicotine plus genistein $(154 \pm 10 \%, \mathrm{p}<0.04 ; \mathrm{n}=10)$, significantly increased LTP compared to that in genistein alone $(\mathrm{p}<0.005)$.

The potential involvement of the tyrosine kinase Src in the induction of LTP was further investigated by examining the effects of two potent and selective Src kinase inhibitors, PP2 and SU-6656 (Sanna et al, 2000; Meriane et al, 2004). Src kinases have previously been demonstrated to alter NMDAR activation (Yu et al, 1997; Lu et al, 1998) and are required in mGluR5 activation of the MAPK signalling cascade (Peavy et 
al, 2001). PP2 ( $1 \mu \mathrm{M})$ completely blocked control HFS induced LTP $(101 \pm 5 \%, \mathrm{p}>0.5$; $\mathrm{n}=5$, 60min post HFS) (Fig. 2B). In contrast, substantial LTP was induced in the presence of nicotine plus PP2 (137 $\pm 2 \%, p<0.001 ; n=5)$, with significantly increased LTP compared to that in PP2 alone $(\mathrm{p}<0.005)$. A second selective Src kinase inhibitor SU-6656 $(10 \mu \mathrm{M})$ produced similar results (Fig. 2C). Thus the induction of control LTP was strongly blocked by SU-6656, with LTP not significantly different from baseline $(110 \pm 3 \%, p>0.1 ; n=6)$. In contrast, substantial LTP was induced in the presence of nicotine plus SU-6656 (137 $\pm 4 \%, p<0.001 ; n=7,60$ min post HFS), with significantly increased LTP compared to that in SU-6656 alone ( $\mathrm{p}<0.005)$.

Inhibition of PI3K has previously been reported to disrupt LTP in the hippocampus (Kelly and Lynch, 2000; Opazo et al, 2003; Man et al 2003; Sanna et al, 2002), with wortmannin blocking LTP associated PI3K phosphorylation (Kelly and Lynch, 2000). Moreover, stimulation of $\alpha 7 \mathrm{nAChR}$ in cultured cortical neurons was shown to activate PI3K (Kihara et al, 2001). Using the fungal metabolite wortmannin which is a potent and highly selective inhibitor of PI3K activation with an IC50 for PI3K of 5-10nM (Davies et al, 2000), we investigated the role of PI3K in nicotinic enhanced LTP. The induction of control HFS-LTP was strongly inhibited by wortmannin $(100 \mathrm{nM}$ or $1 \mu \mathrm{M})$ with LTP measuring $115 \pm 9 \%(\mathrm{p}>0.1 ; \mathrm{n}=1)$ and $102 \pm 6 \%(p>0.8 ; n=7)$ respectively (60 min post HFS) (Fig. 2D, E). The nicotinic enhancement of LTP was less sensitive to inhibition by wortmannin. Thus the induction of nicotinic enhanced LTP was unaffected by the low concentration of wortmannin (100 nM) $(177 \pm 16 \%, p>0.1 ; n=9)$ (Fig. 2D), but was inhibited by the higher concentration

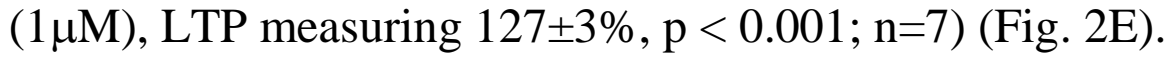

Thus nicotinic-enhancement of LTP, unlike control LTP, is not dependent on activation of the tyrosine kinase Src. Moreover, nicotinic-enhancement of LTP is less dependent on activation of PI3K than control LTP. 


\section{Acute nicotinic enhancement of LTP does not require CaMKII, JAK2 or p38 MAPK activity}

A number of kinases previously reported to couple to nicotinic receptor activation were also investigated. Nicotinic activation of the $\alpha 7 \mathrm{nAChR}$ was previously shown to activate CaMKII (Klein and Yakel, 2005). The selective cell permeable

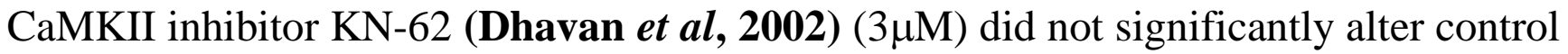
HFS induced LTP $(148 \pm 6 \%, p>0.9 ; n=9)$ (Fig. 3A), confirming a recent study from the present laboratory that LTP induction in the dentate gyrus could not be blocked by inhibition of CaMKII alone, unlike CA1 (Wu et al, 2006). We also found that KN-62 also did not inhibit LTP induced in the presence of nicotine $(202 \pm 8 \%, p>0.4 ; n=5)$ (Fig. 3A).

Previous reports have found that nicotine activation of JAK2 via $\alpha 7$ nAChR's has a neuroprotective role against the Alzheimer's associated protein A $\beta 1-42$ (Shaw et al, 2002; Takada-Takatori et al, 2006). However, in the present study, inhibition of JAK2 kinase with Tyrphostin AG-490 $(10 \mu \mathrm{M})$ (Marrero et al, 2003; Shaw et al, 2003) did not inhibit control HFS-LTP (136 $\pm 11 \%$, p > 0.5; n=5) (Fig. 3B) or LTP induced in the presence of nicotine $(174 \pm 23 \%, \mathrm{p}>0.5 ; \mathrm{n}=5)$.

Finally, p38 MAPK is known to be involved in mGluR dependent LTD in the dentate gyrus (Rush et al, 2002; Wang et al, 2007) but not HFS - LTP (Wang et al, 2004). However, nicotine has been shown to activate p38 MAPK (Wada et al, 2007; Li et al, 2004). The involvement of p38 MAPK in nicotinic enhanced LTP was

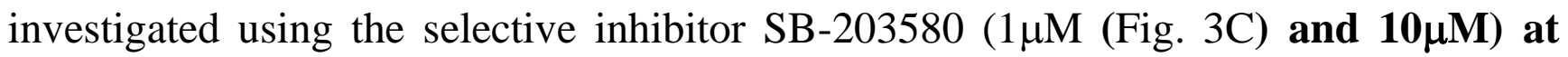
pharmacologically relevant concentrations (Bain et al, 2007; Blanquet, 2000). SB203580 did not inhibit either the induction of control LTP $(159 \pm 11 \%$, p $>0.4 ; n=10)$ or 
LTP induced in the presence of nicotine $(190 \pm 6 \%, \mathrm{p}>0.8 ; \mathrm{n}=5$ @ $\mathbf{1} \mu \mathbf{M}$ and $\mathbf{1 8 8} \pm \mathbf{1 4 \%}$, $p>0.7 ; n=4)$.

Thus nicotinic-enhancement of LTP is not dependent on activation of CaMKII, JAK or p38 MAPK activity.

\section{Chronic nicotine enhancement of LTP is dependent on activation of PKA, ERK and Src kinases}

Previous results from our laboratory have demonstrated that the chronic administration of nicotine $(1 \mathrm{mg} / \mathrm{kg}$ twice daily for two weeks) significantly enhanced HFS induced LTP in the medial perforant pathway of the dentate gyrus in the absence of acute nicotinic receptor activation (Welsby et al, 2006). This result was confirmed in the present studies in which HFS-LTP in nicotine treated rats was significantly enhanced when compared to vehicle controls $(192 \pm 10 \%, \mathrm{p}<0.01 ; \mathrm{n}=7,60 \mathrm{~min}$ post HFS) (Fig. 4A). The kinase dependence of chronic nicotine enhanced LTP was subsequently investigated. The MEK1/2 inhibitor U0126 completely blocked the enhancement of HFS-LTP by chronic nicotine, LTP induced in the presence of U0126 not being different from the saline control (148 $\pm 10 \%, \mathrm{p}>0.7 ; \mathrm{n}=5,60 \mathrm{~min}$ post HFS) (Fig. 4B). In addition, LTP induced in the presence of the PKA inhibitor Rp-8-CPTcAMPs was also not significantly different from saline control LTP $(139 \pm 12 \%, \mathrm{p}>0.8$; $\mathrm{n}=5$, 60min post HFS) (Fig. 4C). Thus the enhancement of induction of LTP caused by chronic nicotine application, although not induction of control LTP, was dependent on activation of ERK and PKA.

The Src kinase inhibitor SU-6656 completely blocked control LTP (Fig. 2A, 4D) and the enhanced LTP following chronic nicotine application, LTP measuring 101 $\pm 3 \%$, $\mathrm{p}>0.5 ; \mathrm{n}=5$ (Fig. 4D). Thus Src is necessary for both control LTP and the chronic nicotine enhancement of LTP. 
The effect of acute nicotine on chronic nicotine enhanced LTP was also examined (Fig. 4E). Chronic nicotine treatment increased the magnitude of LTP significantly $(p<0.05)$ over saline treated controls $(189 \pm 8 \%, n=5$ vs. $159 \pm 9 \%, n=5)$ (Fig. 4E). Additional acute nicotine treatment of hippocampal slices from chronic nicotine treated animals did not further increase the magnitude of LTP $(201 \pm 5 \%$, $\mathbf{p}>0.5 ; n=5)$.

A positive allosteric modulator of the $\alpha 7 \mathrm{nAChR}$ reduces the threshold concentration of nicotine for enhancement of LTP

PNU-120596 is a positive allosteric modulator at the $\alpha 7 \mathrm{nAChR}$ and has been demonstrated to enhance isolated acetylcholine elicited $\alpha 7$ receptor currents (Hurst et al, 2005). In the present studies, PNU-120596 $(1 \mu \mathrm{M})$ did not significantly enhance control LTP $(148 \pm 9 \%, p>0.5 ; n=9,60 \mathrm{~min}$ post HFS) (Fig. 5A) or the maximally enhanced

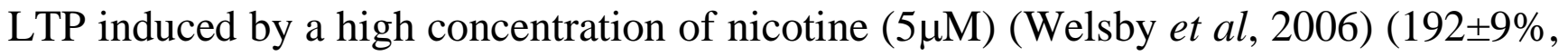
p > 0.5; n=5, 60min post HFS) (Fig. 5B). However, PNU-120596 reduced the threshold concentration of nicotine required to enhance LTP. Thus while $500 \mathrm{nM}$ nicotine alone did not enhance LTP $(157 \pm 12 \%, p>0.6 ; n=8)$ (Fig. 5C), the same concentration of nicotine did significantly enhance LTP in the presence of PNU-120596 (191ะ5\%, p < $0.01 ; n=5$ ) (Fig. 5D). In order to confirm that nicotine was solely activating the $\alpha 7$ nAChR in the presence of PNU-120596, we found that while MLA alone (50nM) had

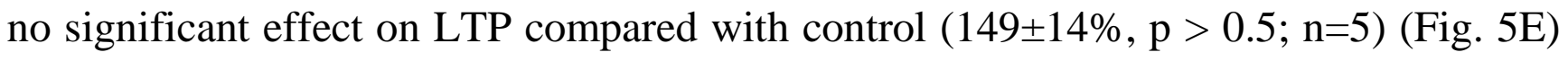
(see also Welsby et al, 2006), MLA completely blocked the enhancement of LTP in the

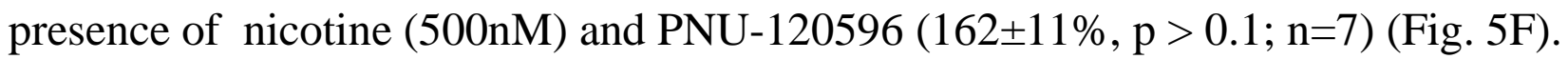

\section{Acetylcholinesterase inhibitors enhance HFS-LTP}

In order to determine if an increase in endogenous acetylcholine levels could enhance HFS-LTP in a manner similar to nicotine the effects of two different AChE 
inhibitors, physostigmine and tacrine, were examined. Physostigmine applied at a concentration of $10 \mu \mathrm{M}$, although not $1 \mu \mathrm{M}$, enhanced HFS-LTP $(179 \pm 11 \%, \mathrm{p}>0.7 ; \mathrm{n}=5$, and $138 \pm 13 \%, \mathrm{p}>0.5 ; \mathrm{n}=5$ respectively) (Fig. 6A). Tacrine $(10 \mu \mathrm{M})$ also produced a strongly enhanced LTP $(181 \pm 8 \%, \mathrm{p}>0.9 ; \mathrm{n}=9$, 60min post HFS) (Fig. 6B). The enhanced LTP in physostigmine and tacrine was identical to that produced by nicotine.

\section{Discussion}

We previously described both acute and chronic nicotinic enhancement of LTP in the perforant pathway of the rat dentate gyrus (Welsby et al, 2006, 2007). In the current studies we have utilized this model to identify a number of kinases critical for the effects of nicotine and also assessed the effectiveness of a number of modulators of cholinergic signalling in mimicking or further augmenting LTP enhancement. We find that activation of ERK and PKA is required for the acute nicotinic enhancement of LTP but not control LTP, while activation of PI3K and Src is required for control LTP but not acute nicotinic-enhancement of LTP. Moreover, chronic nicotine enhancement of LTP is dependent on PKA, ERK and Src kinases.

The involvement of the kinases PKA and ERK1/2 MAPK in LTP and memory processes has been demonstrated in a number of previous studies. Transgenic mice over-expressing a dominant negative form of the PKA regulatory subunit showed significantly reduced LTP in the CA1 region of the hippocampus (Abel et al, 1997; Woo et al, 2000) while inhibitors of PKA prevent the induction of early and late phase LTP in vitro (Blitzer et al, 1995, 1998; Huang and Kandel 1994; Matthies and Reymann 1993). Many in vivo studies have demonstrated a role for the cAMP/PKA pathway in memory. Acute infusion of modulators of PKA activity into the CA1 region altered spatial memory in the Morris water maze task in male rats (Sharifzadeh et al, 2005, 2007); infusion of the PKA inhibitor H-89 impaired spatial memory retention in trained animals (Sharifzadeh et al, 2005); and conversely the membrane permeable PKA 
activator dibutyryl cyclic AMP caused a significant improvement in special memory (Sharifzadeh et al, 2007). ERK1/2 MAPK has also been implicated in synaptic plasticity and memory. The formation of contextual and spatial memories in mammals has requires activation of ERK/MAPK (Sweatt, 2001) and various inhibitors of the ERK1/2 pathway also attenuate LTP induction in CA1 (English and Sweatt, 1997; Davis et al, 2000; Ying et al, 2002). However, in the dentate gyrus, control LTP is mediated by the induction of one of two parallel pathways (Wu et al, 2006), the first requiring CaMKII activation and the second PKA or MAPK. The involvement in nicotine activated PKA in synaptic plasticity is less well described. In vitro studies using SH-SY5Y cells and cultured hippocampal neurones have previously shown that acute activation of the $\alpha 7$ nAChR stimulates ERK1/2 via PKA activation (DajasBailador et al, 2002). An interaction between PKA and ERK1/2 following nicotine stimulation may also occur during LTP enhancement. Our studies found that the acute inhibition of PKA and MEK, the kinase immediately upstream from ERK1/2, did not alter induction of control LTP but completely prevented nicotinic augmentation of LTP. Thus activation of the $\alpha 7$ nAChR links to stimulation of the PKA and MEK intracellular signalling pathways and thence enhances LTP induction.

The enhanced HFS-LTP following chronic nicotine treatment was also dependent on PKA and ERK activation. The chronic enhancement of LTP may be due to alterations in the expression of proteins in the cAMP-PKA signalling pathway following chronic nicotine treatment. It has been shown that in the brains of human smokers both PKA and adenylate cyclase levels are increased (Hope et al, 2007). Also, in rats chronically exposed to nicotine, phosphodiesterase levels are decreased (Polesskaya et al, 2007a, b). It is also known that both PKA and adenylate cyclase demonstrate basal activity in the absence of agonist activation (Bogan and Niswender, 2007; Salazar and Gonzalez, 2002). Under control conditions inhibition of this basal activity does not impact on LTP induction. However, nicotine induced upregulation of 
the pathway at least in part may be responsible for enhanced HFS-LTP in the absence of acute nAChR activation. This hypothesis is supported by a study showing that repetitive activation of PKA induces a persistent potentiation in fEPSP amplitude recorded from the CA1 region in cultured hippocampal slices (Tominaga-Yoshino et al, 2002).

Src kinases have been implicated previously in LTP induction and $\alpha 7 \mathrm{nAChR}$ functioning. Thus tyrosine phosphorylation of the NMDAR and Src mediated insertion of AMPAR's are required for LTP induction in vitro (Casey et al, 2002; Huang and Hsu 1999; O’Dell et al, 1991). Conversely, phosphorylation of the $\alpha 7 \mathrm{nAChR}$ by Src kinase reduces acetylcholine evoked currents and decreases receptor expression at the cell surface (Charpantier et al, 2005; Cho et al, 2005). Block of Src kinase activation prevented the induction of control LTP in our present studies but did not prevent the acute nicotine enhancement of LTP component. In contrast, the enhancement of LTP by chronic nicotine treatment was found to be dependent on Src activation, further evidence for different mechanisms underlying acute and chronic enhancement of LTP as well as control LTP and nicotinic-enhanced LTP.

HFS induced LTP in the dentate gyrus has previously been shown to require PI3K activation (Kelly and Lynch, 2000; Opazo et al, 2003; Man et al 2003; Sanna et al, 2002), a finding that our studies confirm and additionally establish that control and nicotinic enhancement of LTP display differential sensitivities to PI3K inhibition. In the present studies, concentrations of wortmanin sufficient to block control plasticity did not block nicotinic-enhanced LTP, although such nicotinic-enhanced LTP was inhibited using a higher although still selective concentration of the PI3K antagonist (Davies et al, 2000). This result shows that nicotinic-enhanced LTP is less dependent on activation of PI3K than control LTP. The activation of PI3K following $\alpha 7 \mathrm{nAChR}$ stimulation reported by Kihara et al and others (Shaw et al, 2002) established a neuroprotective role for nicotine in $\mathrm{AD}$. This neuroprotective pathway and the nicotinic enhancement of LTP 
which we describe appear to diverge following receptor activation but both involve PI3K adding further complexity to the many reported effects of nicotine treatment.

Hippocampal cholinergic deficits associated with $\mathrm{AD}$ have been treated with partial success through modulation of endogenous signalling with drugs such as galantamine which acts as both an inhibitor of AChE and as a positive allosteric modulator at nAChR's (Santos et al, 2002). Modulation of endogenous signalling may avoid both over stimulation and desensitisation associated with direct agonist stimulation and also problems with agonist selectivity due to the high sequence homology of nAChR orthosteric binding sites and also other members of the cys-loop family. To date a number of positive allosteric modulators of the $\alpha 7 \mathrm{nAChR}$ have been described including PNU-120596 which was demonstrated to have therapeutic potential by improving auditory gating deficits (Hurst et al, 2005). Our current studies found a lack of effect of acute PNU-120596 on LTP in the absence of exogenous agonist activation. However, acute PNU-120596 did produce an approximate tenfold reduction in the threshold for nicotinic enhancement of LTP. We also showed that control LTP is increased by tacrine in a manner consistent with its primary activity as an AChE inhibitor and thus enhancement of HFS released acetylcholine (Liston et al, 2004). A similar enhancement was produced by physostigmine which has activity both as an AChE inhibitor (Atack et al, 1989) and as a positive allosteric modulator of $\alpha 7$ nAChRs (Faghih et al, 2008). However given the lack of affect of PNU-120596, a drug reported not to inhibit AChE activity but to modulate positively the activity of $\alpha 7$ nAChRs through an allosteric site (Hurst et al, 2005), it is reasonable to conclude that the enhancement of control LTP by physostigmine and tacrine is as a result of AChE inhibition and not allosteric modulation.

In summary, this study shows that the control and nicotine enhanced components of HFS-LTP in the perforant pathway of the rat dentate gyrus display diverse and 
differential kinase sensitivities. Allosteric modulation of $\alpha 7 \mathrm{nAChR}$ signalling reduces the threshold for nicotinic enhancement of HFS-LTP and inhibition of AChE activity enhances HFS-LTP in a manner consistent with $\alpha 7 \mathrm{nAChR}$ activation. This information and further characterisation of nicotine enhanced LTP will aid in the development of novel cholinergic treatments for AD.

Acknowledgements: This work was supported by Trinity College Institute of Neuroscience and the Science Foundation, Ireland

Abbreviations: AD, Alzheimer's disease; LTP, long-term potentiation; nAChR, nicotinic acetylcholine receptor; ERK, extracellular signal-regulated kinase; PKA, cAMP-dependent protein kinase; CaMKII, $\mathrm{Ca}^{2+}$-calmodulin-regulated kinase II; JAK, Janus kinase; MAPK, mitogen-activated protein kinase; PI3K, phosphoinositide 3kinase; AChE, acetylcholinesterase; EPSP, excitatory-postsynaptic potential; HFS, high frequency stimulation; MEK, mitogen activated protein kinase kinase; MLA, methyllycaconitine 


\section{References}

Abel, T., Nguyen, P.V., Barad, M., Deuel, T.A., Kandel, E.R. \& Bourtchouladze, R. (1997) Genetic demonstration of a role for PKA in the late phase of LTP and in hippocampus-based long-term memory. Cell, 88(5), 615-26.

Arendt, T., Bruckner, M.K., Bigl, V. \& Marcova, L. (1995) Dendritic reorganisation in the basal forebrain under degenerative conditions and its defects in Alzheimer's disease. II. Ageing, Korsakoff's disease, Parkinson's disease and Alzheimer's disease. J. Comp. Neurol., 351, 189-222.

Atack, J.R., Yu, Q.S., Soncrant, T.T., Brossi, A. \& Rapoport, S.I. (1989) Comparative inhibitory effects of various physostigmine analogs against acetyl- and butyrylcholinesterases. J. Pharmacol. Exp. Ther., 249: 194-202.

Bain, J., Plater, L., Elliott, M., Shpiro, N., Hastie, J., McLauchlan, H., Klevernic, I., Arthur, J.S.C., Alessi, D.R. \& Cohen, P. (2007) The selectivity of protein kinase inhibitors: a further update. Biochem. J. 408, 297-315.

Bear, M.F. \& Malenka, R.C. (1994) Synaptic Plasticity: LTP and LTD. Curr. Opin. Neurobiol., 4, 389-399.

Blanquet, P.R. (2000) Identification of two persistently activated neurotrophinregulated pathways in rat hippocampus. Neurosci. 95(3), 705-719.

Bliss, T.V. \& Collingridge, G.L. (1993) A synaptic model of memory: long-term potentiation in the hippocampus. Nature, 361, 31-39.

Blitzer, R.D., Wong, T., Nouranifar, R., Iyengar, R. \& Landau, E.M. (1995) Postsynaptic cAMP pathway gates early LTP in hippocampal CA1 region. Neuron, 15(6), 1403-14. 
Blitzer, R.D., Connor, J.H., Brown, G.P., Wong, T., Shenolikar, S., Iyengar, R. \& Landau, E.M. (1998) Gating of CaMKII by cAMP-regulated protein phosphatase activity during LTP. Science, 280(5371), 1940-2.

Bogan, R.L. \& Niswender, G.D. (2007) Constitutive steroidogenesis in ovine large luteal cells may be mediated by tonically active protein kinase A. Biol. Reprod., 77(2), 209-16.

Casey, M., Maguire, C., Kelly, A., Gooney, M.A. \& Lynch, M.A. (2002) Analysis of the presynaptic signalling mechanisms underlying the inhibition of LTP in rat dentate gyrus by the tyrosine kinase inhibitor, Genistein. Hippocampus, 12, 377-385.

Charpantier, E., Wiesner, A., Huh, K.H., Ogier, R., Hoda, J.C., Allaman, G., Raggenbass, M., Feuerbach, D., Bertrand, D. \& Fuhrer, C. (2005) $\alpha 7$ neuronal nicotinic acetylcholine receptors are negatively regulated by tyrosine phosphorylation and Srcfamily kinases. J. Neurosci., 25(43), 9836-9849.

Cho, C.H., Song, W., Leitzell, K., Teo, E., Meleth, A.D., Quick, M.W. \& Lester, R.A.J. (2005) Rapid upregulation of $\alpha 7$ nicotinic acetylcholine receptors by tyrosine dephosphorylation. J. Neurosci., 25(14), 3712-3723.

Dajas-Bailador, F.A., Soliakov, L. \& Wonnacott, S. (2002) Nicotine activates the extracellular signal-regulated kinase $1 / 2$ via the $\alpha 7$ nicotinic acetylcholine receptor and protein kinase A, in SH-SY5Y cells and hippocampal neurones. J. Neurochem., 80, 520-530.

Davies, S.P., Reddy, H., Caivano, M. \& Cohen, P. (2000) Specificity and mechanism of action of some commonly used protein kinase inhibitors. Biochem. J., 351, 95-105. 
Davis, S., Vanhoutte, P., Pages, C., Caboche, J. \& Laroche, S. (2000) The MAPK/ERK cascade targets both Elk-1 and cAMP response element-binding protein to control longterm potentiation-dependent gene expression in the dentate gyrus in vivo. J. Neurosci. 20(12), 4563-72.

Decker, M.W. \& McGaugh, J.L. (1991) The role of interactions between the cholinergic system and other neuromodulatory systems in learning and memory. Synapse, 7, 151168.

Dhavan, R., Greer, P.L., Morabito, M.A., Orlando, L.R. \& Tsai, L.H. (2002) The cyclin-dependent kinase 5 activators p35 and p39 interact with the $\alpha$-subunit of $\mathrm{Ca}^{2+} /$ calmodulin-dependent proteins kinase II and $\alpha$-actinin-1 in a calciumdependent manner. J. Neurosci. 22(18), 7879-7891.

Dominguez del Toro, E., Juis, J.M., Peng, X., Lindstrom, J. \& Criado, M. (1994) Immunocytochemical localisation of the alpha 7 subunit of the nicotinic acetylcholine receptor in the rat central nervous system. J. Comp. Neurol., 349, 325-342.

English, J.D. \& Sweatt, J.D. (1997) A requirement for the mitogen-activated protein kinase cascade in hippocampal long term potentiation. J. Biol. Chem., 272(31), 19103-6.

Faghih, R., Gopalakrishnan, M. \& Briggs, C.A. (2008) Allosteric modulators of the $\alpha 7$ nicotinic acetylcholine receptor. J. Med. Chem., 51(4), 701-712.

Fujii, S., Ji, X., Morita, N. \& Sumikawa, K. (1999) Acute and chronic nicotine exposure differentially facilitate the induction of LTP. Brain Res, 846, 137-143.

Giovannini, M.G., Efoudebe, M., Passani, M.B., Baldi, E., Bucherelli, C., Giachi, F., Corradetti, R. \& Blandina, P. (2003) J. Neurosci. 23(27), 9016-9023. 
Gray, R., Rajan, A.S., Radcliffe, K.A., Yakehiro, M. \& Dani, J.A. (1996) Hippocampal synaptic transmission enhanced by low concentrations of nicotine. Nature, 383, 713716.

Hope, B.T., Nagarkar, D., Leonard, S. \& Wise, R.A. (2007) Long-term upregulation of protein kinase A and adenylate cyclase levels in human smokers. J. Neurosci., 27(8), 1964-1972.

Huang, C-C. \& Hsu, K.S. (1999) Protein tyrosine kinase is required for the induction of long-term potentiation in the rat hippocampus. J. Physiol., 520(3), 783-796.

Huang, Y.Y. \& Kandel, E.R. (1994) Recruitment of long-lasting and protein kinase Adependent long-term potentiation in the CA1 region of hippocampus requires repeated tetanization. Learn. Mem., 1994 1(1), 74-82.

Hunter, B.E., de Fiebre, C.M., Papke, R.L., Kem, W.R. \& Meyer, E.M. (1994) A novel nicotinic agonist facilitates induction of long-term potentiation in the rat hippocampus. Neurosci. Lett., 168(1-2), 130-134.

Hurst, R.S., Hajos, M., Raggenbass, M., Wall, T.M., Higdon, N.R., Lawson, J.A., Rutherford-Root, K.L., Berkenpas, MB., Hoffmann, W.E., Piotrowski, D.W., Groppi, V.E., Allarman, G., Ogier, R., Bertrand, S., Bertrand, D. \& Arneric, S.P. (2005) A novel positive allosteric modulator of the $\alpha 7$ neuronal nicotinic acetylcholine receptor: in vitro and in vivo characterisation. J. Neurosci., 25(17), 4396-4405.

Ji, D., Lape, R. \& Dani, J.A. (2001) Timing and location of nicotinic activity enhances or depresses hippocampal synaptic plasticity. Neuron, 31, 131-41.

Jones, S., Sudweeks, S. \& Yakel, J.L. (1999) Nicotinic receptors in the brain: correlating physiology with function. Trends Neurosci., 22, 555-561. 
Kawakami, M., Sekiguchi, M., Sato, K., Kozaki, S. \& Takahashi, M. (2001) Erythropoietin receptor-mediated inhibition if exocytotic glutamate release confers neuroprotection during chemical ischemia. J. Biol. Chem. 276(42), 3946939475.

Kelly, A., Lynch, M.A. (2000) Long-term potentiation in the dentate gyrus of the rat is inhibited by the phosphoinositide 3-kinase inhibitor, wortmannin. Neuropharmacol., 39, 643-651.

Kihara, T., Shimohama, S., Sawada, H., Honda, K., Nakamizo, T., Shibasaki, H., Kume, T. \& Akaike, A. (2001) $\alpha 7$ nicotinic receptor transduces signals to phosphatidylinositol 3-kinase to block A $\beta$-amyloid-induced neurotoxicity. J. Biol. Chem., 276(17), 1354113546.

Klein, R.C. \& Yakel, J.L. (2005) Paired-pulse potentiation of $\alpha 7$-containing nAChR's in rat hippocampal CA1 stratum radiatum interneurons. J. Physiol., 568(3), 881-889.

Krause, R.M., Buisson, B., Bertrand, S., Corringer, P.J., Galzi, J.L., Changeux, J.P. \& Bertrand, D. (1998) Ivermectin: a positive allosteric effector of the alpha7 nicotinic acetylcholine receptor. Mol. Pharmacol., 53, 283-294.

Le Novere, N. \& Changeux, J.P. (1995). Molecular evolution of the nicotinic acetylcholine receptor: an example of multigene family in excitable cells. J. Mol. Evol. 40, 155-172.

Levin, E.D. (2002) Nicotinic receptor subtypes and cognitive function. J. Neurobiol. 53, 633-640.

Li, J.M., Cui, T.X., Shiuchi, T., Liu, H.W., Min, L.J., Okumura, M., Jinno, T., Wu, L., Iwai, M. \& Horiuchi, M. (2004) Nicotine enhances angiotensin II-induced mitogenic 
response in vascular smooth muscle cells and fibroblasts. Arterioscler. Thromb. Vasc. Biol. 24, 80-84.

Liston, D.R., Nielsen, J.A., Villalobos, A., Chapin, D., Jones, S.B., Hubbard, S.T., Shalaby, I.A., Ramirez, A., Nason, D. \& White, W.F. (2004) Pharmacology of selective acetylcholinesterase inhibitors: implications for use in Alzheimer's disease. Eur. J. Pharmacol. 486, 9-17.

Lu, Y.M., Roder, J.C., Davidow, J. \& Salter, M.W. (1998) Src activation in the induction of long-term potentiation in CA1 hippocampal neurons. Science 279, 13631367.

Man, H.Y., Wang, Q., Lu, W.Y., Ju, W., Ahmadian, G., Liu, L., D’Souza, S., Wong, T.P., Taghibiglou, C., Lu, J., Becker, L.E., Pei, L., Liu, F., Wymann, M.P., MacDonald, J.F. \& Wang, Y.T. (2003) Activation of PI3-kinase is required for AMPA receptor insertion during LTP of mEPSC's in cultured hippocampal neurons. Neuron 38, 611624.

Mann, E.O. \& Greenfield, S.A. (2003) Novel modulatory mechanisms revealed by the sustained application of nicotine in the guinea-pig hippocampus in vitro. J. Physiol. 551, 539-550.

Marrero, M.B., Papke, R.L., Bhatti, B.S., Shaw, S. \& Bencherif, M. (2003) The neuroprotective effect of 2-(3-pyridyl)-1-azabicyclo[3.2.2]nonane (TC-1698), a novel $\alpha 7$ ligand, is prevented through angiotensin II activation of a tyrosine phospatase. J. Pharmacol. Exp. Ther. 309(1), 16-27.

Matsuyama, S., Matsumoto, A., Enomotot, T. \& Nishizaki, T. (2000) Activation of nicotinic acetylcholine receptors induces long-term potentiation in vivo in the intact mouse dentate gyrus. Eur. J. Neurosci. 12, 3741-3747. 
Matthies, H. \& Reymann, K.G. (1993) Protein kinase A inhibitors prevent the maintenance of hippocampal long-term potentiation. Neuroreport 4(6), 712-4.

\section{Meriane, M., Tcherkezian, J., Webber, C.A., Danek, E.I., Triki, I., McFarlane, S., Bloch-Gallego, E. \& Lamarche-Vane, N. (2004) J. Cell Biol. 167(4), 687-698.}

O’Dell, T.J., Kandel, E.R. \& Grant, S.G.N. (1991) Long-term potentiation in the hippocampus is blocked by tyrosine kinase inhibitors. Nature 353, 558-560.

Opazo, P., Watabe, A.M., Grant, S.G.N. \& O’Dell, T.J. (2003) Phosphatidylinsitol 3kinase regulates the induction of long-term potentiation through extracellular signalregulated kinase-independent mechanisms. J. Neurosci. 23(9), 3679-3688.

Peavy, R.D., Chang, M.S.S., Sanders-Bush, E. \& Conn, P.J. (2001) Metabotropic glutamate receptor 5-induced phosphorylation of extracellular signal-regulated kinase in astrocytes depends on transactivation of the epidermal growth factor receptor. $J$. Neurosci. 21(24), 9619-9628.

Picciotto, M.R., Caldarone, B.J., Brunzell, D.H., Zachariou, V., Stevens, T.R. \& King, S.L. (2001). Neuronal nicotinic acetylcholine receptor subunit knockout mice: physiological and behavioural phenotypes and possible clinical implications. Pharmacol. Ther. 92, 89-108.

Polesskaya, O.O., Smith, R.F. \& Fryxell, K.J. (2007a) Chronic nicotine doses downregulate PDE4 isoforms that are targets of antidepressants in adolescent female rats. Biol. Psychiatry 61(1), 56-64.

Polesskaya, O.O., Fryxell, K.J., Merchant, A.D., Locklear, L.L., Ker, K.F., McDonald, C.G., Eppolito, A.K., Smith, L.N., Wheeler, T.L. \& Smith, R.F. (2007b) Nicotine 
causes age-related changes in gene expression in the adolescent female rat brain. Neurotoxicol. Teratol. 29, 126-140.

Radcliffe, K.A. \& Dani, J.A. (1998) Nicotinic stimulation produces multiple forms of increased glutamatergic synaptic transmission. J. Neurosci. 18, 7075-7083.

Roberson, E.D., English, J.D., Adams, J.P., Selcher, J.C., Kondratick, C. \& Sweatt, J.D. (1999) The mitogen-activated protein kinse cascade couples PKA and PKC to cAMP response element binding protein phosphorylation in area CA1 of hippocampus. J. Neurosci. 19(11), 4337-4348.

Rush, A.M., Wu, J., Rowan, R.J. \& Anwyl, R. (2002) Group 1 metabotropic glutamate receptor (mGluR)-dependent long-term depression mediated via p38 mitogen-activated protein kinase is inhibited by previous high-frequency stimulation and activation of mGluRs and protein kinase C in the rat dentate gyrus in vitro. J. Neurosci. 22(14), 6121-6128.

Salazar, G. \& González, A. (2002) Novel mechanism for regulation of epidermal growth factor receptor endocytosis revealed by protein kinase A inhibition. Mol. Biol. Cell. 13(5), 1677-93.

Sanna, P.P., Berton, F., Cammalleri, M., Tallent, M.K., Siggins, G.R., Bloom, F.E. \& Francesconi, W. (2000) A role for Src kinase in spontaneous epileptiform activity in the CA3 regions of the hippocampus. PNAS 97(15), 8653-8657.

Sanna, P.P., Cammalleri, M., Berton, F., Simpson, C., Lutjens, R., Bloom, F.E. \& Francesconi, W. (2002) Phosphatidylinsitol 3-kinase in required for the expression but not for the induction or the maintenance of long-term potentiation in the hippocampal CA1 region. J. Neurosci. 22(9), 3359-3365. 
Santos, M.D., Alkondon, M., Pereira, E.F., Aracava, Y., Eisenberg, H.M., Maelicke, A. \& Albuquerque, E.X. (2002) The nicotinic allosteric potentiating ligand galantamine facilitates synaptic transmission in the mammalian central nervous system. Mol. Pharmacol. 61(5), 1222-34.

Seguela, P., Wadiche, J., Dineley-Miller, K., Dani, J.A. \& Patrick, J.W. (1993) Molecular cloning, functional properties and distribution of rat brain $\alpha 7$ : a nicotinic cation channel highly permeable to calcium. J. Neurosci. 13, 596-604.

Sharifzadeh, M., Sharifzadeh, K., Naghdi, N., Ghahremani, M.H. \& Roghani, A. (2005) Posttraining intrahippocampal infusion of a protein kinase AII inhibitor impairs spatial memory retention in rats. J. Neurosci. Res. 79(3), 392-400.

Sharifzadeh, M., Zamanian, A.R., Gholizadeh, S., Tabrizian, K., Etminani, M., Khalaj, S., Zarrindast, M.R. \& Roghani, A. (2007) Post-training intrahippocampal infusion of nicotine-bucladesine combination causes a synergistic enhancement effect on spatial memory retention in rats. Eur. J. Pharmacol. 562(3), 212-20.

Sharma, G. \& Vijayaraghavan, S. (2003) Modulation of presynaptic store calcium induces release of glutamate and postsynaptic firing. Neuron 38, 929-39.

Shaw, S., Bencherif, M. \& Marrero, M.B. (2002) Janus Kinase 2, an early target of $\alpha 7$ nicotinic acetylcholine receptor-mediated neuroprotection against A $\beta-(1-42)$ Amyloid. J. Biol. Chem. 277(47), 44920-44924.

Shaw, S., Bencherif, M. \& Marrero, M.B. (2002) Angiotensin II blocks nicotinemediated neuroprotection against $\beta$-amyloid (1-42) via activation of the tyrosine phosphatase SHP-1. J. Neursci. 23(35), 11224-11228. 
Sweatt, J.D. (2001). The neuronal MAP kinase cascade: a biochemical signal integration system subserving synaptic plasticity and memory. J. Neurochem. 76, 1-10.

Takada-Takatori, Y., Kume, T., Sugimoto, M., Katsuki, H., Sugimoto, H. \& Akaike, A. (2006) Acetylcholinesterase inhibitors used in treatment of Alzheimer's disease prevent glutamate neurotoxicity via nicotinic acetylcholine receptors and phosphatidylinositol 3-kinase cascade. Neuropharmacology 51, 474-486.

Tominaga-Yoshino, K., Kondo, S., Tamotsu, S. \& Ogura, A. (2002) Repetitive activation of protein kinase A induces slow and persistent potentiation associated with synaptogenesis in cultured hippocampus. Neurosci. Res. 44(4), 357-67.

Wada, T., Naito, M., Kenmochi, H., Tsuneki, H. \& Sasaoka, T. (2007) Chronic nicotine exposure enhances insulin-induced mitogenic signalling via up-regulation of $\alpha 7$ nicotinic receptors in isolated rat aortic smooth muscle cells. Endocrinology 148(2), 790-799.

Wang, Q., Chang, L., Rowan, M.J. \& Anwyl, R. (2007) Developmental dependence, the role of the kinases p38 MAPK and PKC, and the involvement of tumor necrosis factorR1 in the induction of mGlu-5 LTP in the dentate gyrus. Neuroscience 144, 110-118.

Wang, Q., Walsh, D.M., Rowan, M.J., Selkoe, D.J. \& Anwyl, R. (2004) Block of longterm potentiation by naturally secreted and synthetic amyloid $\beta$-peptide in hippocampal slices is mediated via activation of the kinases c-Jun N-terminal kinase, cyclindependent kinase 5, and p38 mitogen activated protein kinase as well as metabotropic glutamate receptor type 5. J. Neurosci. 24(13), 3370-3378.

Welsby, P.J., Rowan, M. \& Anwyl, R. (2006) Nicotinic receptor-mediated enhancement of long-term potentiation involves activation of metabotropic glutamate receptors and 
ryanodine - sensitive calcium stores in the dentate gyrus. Eur. J. Neurosci. 24, 31093118.

Welsby, P.J., Rowan, M. \& Anwyl, R. (2007) Beta-amyloid blocks high frequency stimulation induced LTP but not nicotine enhanced LTP. Neuropharmacology 53(1), 188-95.

Whitehouse, P.J., Price, D.L., Struble, R.G., Clark, A.W., Coyle, J.T. \& Delon, M.R. (1982) Alzheimer's disease and senile dementia: loss of neurons in the basal forebrain. Science 215, 1237-1239.

Woo, N.H., Duffy, S.N., Abel, T. \& Nguyen, P.V. (2000) Genetic and pharmacological demonstration of differential recruitment of cAMP-dependent protein kinases by synaptic activity. J. Neurophysiol. 84(6), 2739-45.

Wu, J., Rowan, M.J. \& Anwyl, R. (2006) Long-term potentiation is mediated by multiple kinase cascades involving CaMKII or either PKA or p42/44 MAPK in the adult rat dentate gyrus in vitro. J. Neurophysiol. 95, 3519-3527.

Yang, L., Nakayama, Y., Hattori, N., Liu, B. \& Inagaki, C. (2008) GABA - $^{-}$ receptor stimulation activates cAMP-dependent protein kinase via A-kinase anchoring protein 220. J. Pharmacol. Sci. 106, 578-584.

Ying, S.W., Futter, M., Rosenblum, K., Webber, M.J., Hunt, S.P., Bliss, T.V. \& Bramham, C.R. (2002) Brain-derived neurotrophic factor induces long-term potentiation in intact adult hippocampus: requirement for ERK activation coupled to CREB and upregulation of Arc synthesis. J. Neurosci. 22(5), 1532-40.

Yu, X.M., Askalan, R., Keil, G.J. \& Salter, M.W. (1997) NMDA channel regulation by channel-associated protein tyrosine kinase Src. Science 275, 674-678. 
Zhang, J. \& Berg, D.K. (2007) Reversible inhibition of $\mathrm{GABA}_{\mathrm{A}}$ receptors by $\alpha 7-$ containing nicotinic receptors on the vertebrate postsynaptic neurons. J. Physiol. 579 (3), 753-763.

Zwart, R., De Filippi, G., Broad, L.M., McPhie, G.I., Pearson, K.H., Baldwinson, T. \& Sher, E. (2002) 5-Hydroxyindole potentiates human alpha7 nicotinic receptor-mediated responses and enhances acetylcholine-induced glutamate release in cerebellar slices. Neuropharmacol. 43, 374-384. 


\section{Legends}

Fig 1. Kinase dependence of control and nicotinic enhanced HFS-LTP in rat dentate gyrus. A, The graph shows the induction of control LTP (filled circles) and the enhancement of LTP induction by pre-application of nicotine ( $5 \mu \mathrm{M})$ (open circles). B, Acute application of the MEK1/2 inhibitor U0126 $(5 \mu \mathrm{M})$ prevents nicotine enhancement of HFS-LTP (closed circles). C, The PKA inhibitor H-89 $(2 \mu \mathrm{M})$ blocks nicotine enhancement of HFS-LTP (closed circles). D, A non-hydrolysable analogue of cAMP, Rp-8-CPT-cAMPs $(100 \mu \mathrm{M})$, prevents nicotinic enhancement of HFS-LTP (closed circles). Traces illustrate EPSP’s before and 60min after HFS. 

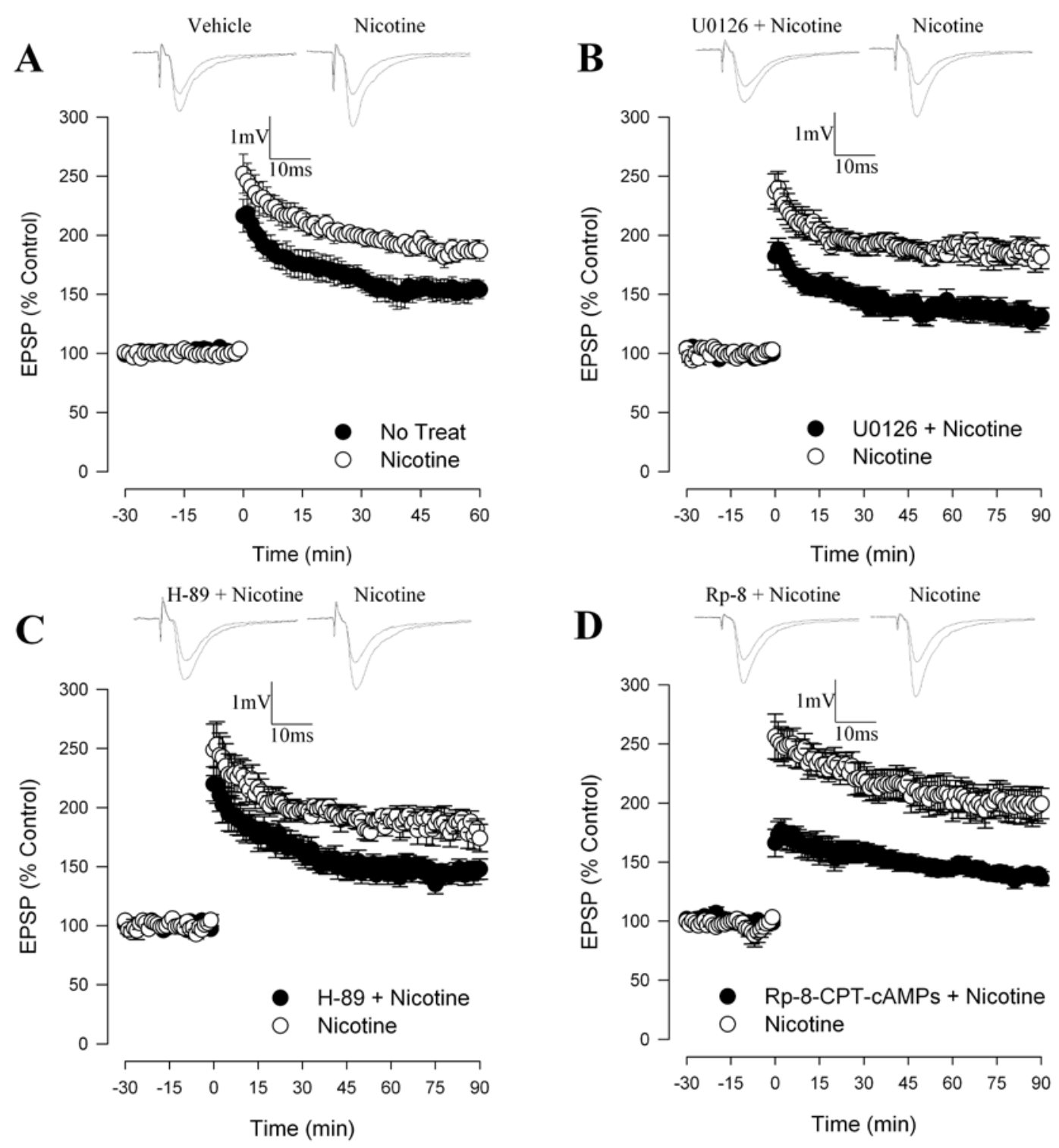
Fig 2. Kinase dependence of control and nicotine enhanced HFS-LTP in the rat dentate gyrus. A, The graph shows the induction of LTP in control (filled circles) and nicotine treated (open circles) slices in the presence of the tyrosine kinase inhibitor genistein $(10 \mu \mathrm{M})$. B, The Src kinase inhibitor PP2 $(1 \mu \mathrm{M})$ blocks control LTP (closed circles) and reduces the magnitude of nicotinic enhanced LTP (open circles). C, SU$6656(10 \mu \mathrm{M})$ also blocks control HFS-LTP (closed circles) but HFS-LTP in the presence of nicotine remains significantly above baseline (open circles). D, A concentration of wortmannin $(100 \mathrm{nM})$ sufficient to completely block control HFS-LTP (closed circles) does not significantly affect nicotinic enhancement of LTP (open circles). E, A higher concentration of wortmannin $(1 \mu \mathrm{M})$ inhibits nicotinic LTP (open circles) however, LTP remains significantly above baseline. Traces illustrate EPSP's before and 60min after HFS. 

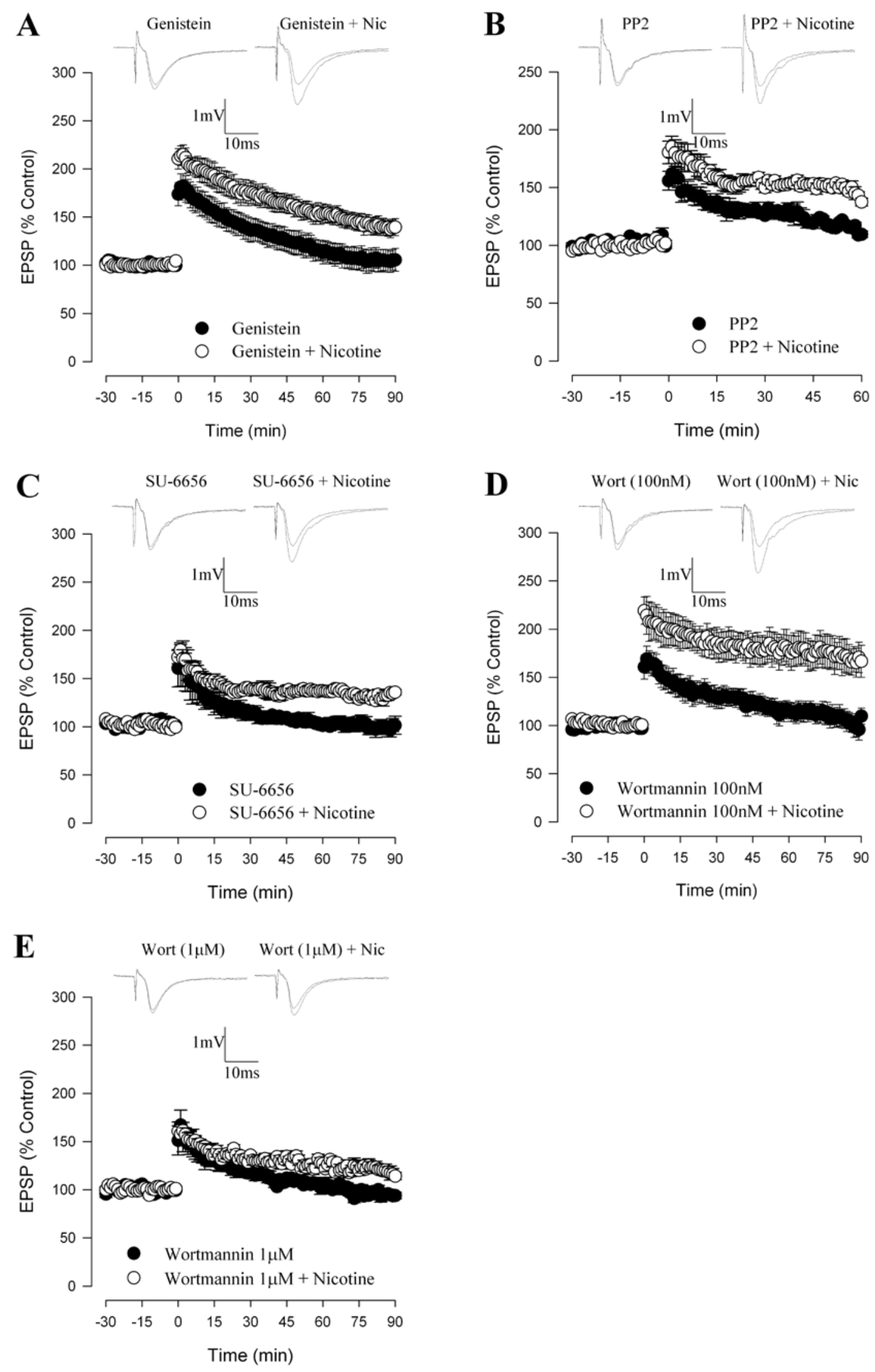
Fig 3. Acute nicotinic enhancement of LTP is not dependent on CaMKII, JAK or p38 MAPK activation. A, Induction of control LTP is unaffected by the selective

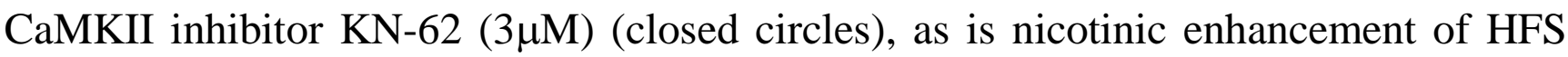
induced LTP (open circles). B, Acute application of the JAK inhibitor tyrphostin AG$490(10 \mu \mathrm{M})$ affects neither control (closed circles) nor nicotine enhanced (open circles) C, The selective p38 MAPK inhibitor SB-205380 $(1 \mu \mathrm{M})$ also does not block control (closed circles) or nicotine enhanced LTP (open circles) in the rat dentate gyrus. Traces illustrate EPSP's before and 60min after HFS. 

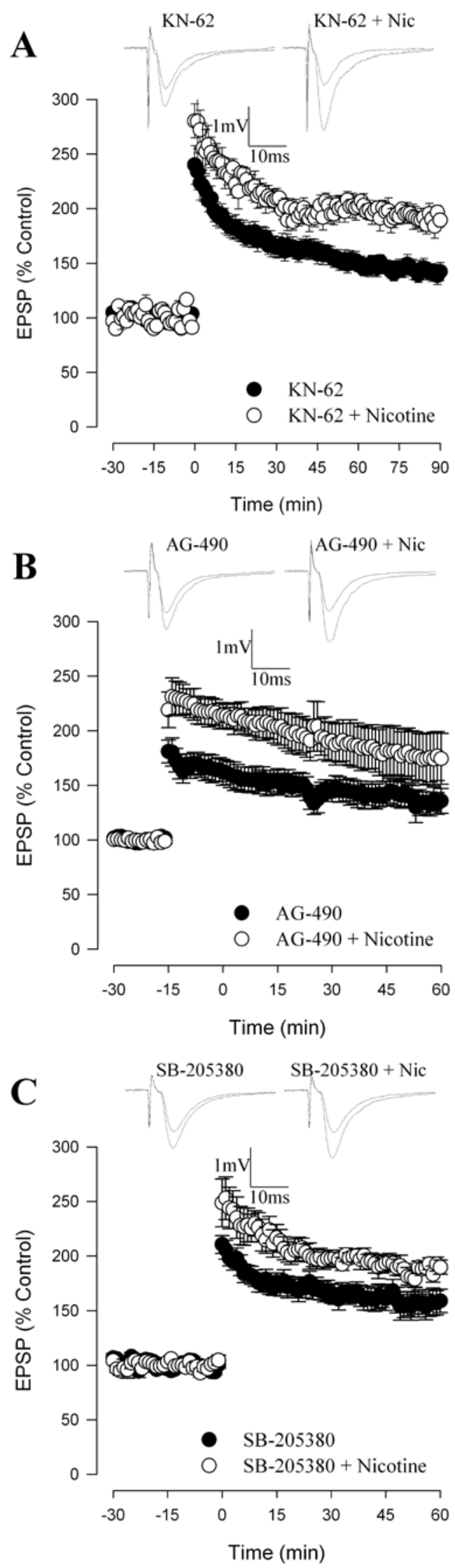
Fig 4. Chronic nicotine enhanced HFS-LTP is dependent on ERK1/2, PKA and Src family kinase activation in the rat dentate gyrus. A, Chronic treatment with nicotine (1mg/kg twice daily for two weeks) significantly enhances HFS-LTP (open circles) in the absence of acute nicotine when compared with saline control (closed circles). B,

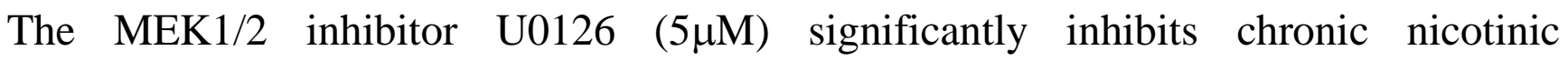
enhancement of HFS-LTP (open circles). C, The PKA inhibitor Rp-8-CPT-cAMPs $(100 \mu \mathrm{M})$ also inhibits chronic nicotine enhanced LTP (open circles). D, SU-6656 $(10 \mu \mathrm{M})$, the Src family kinase inhibitor completely blocks LTP following chronic

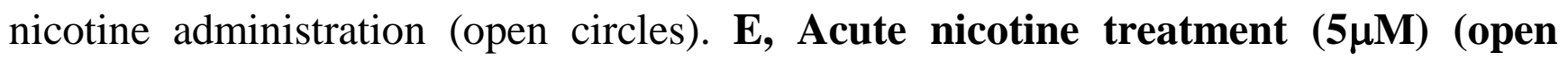
circles) does not enhance LTP significantly over chronic nicotine treatment. Traces illustrate EPSP's before and 60min after HFS. 

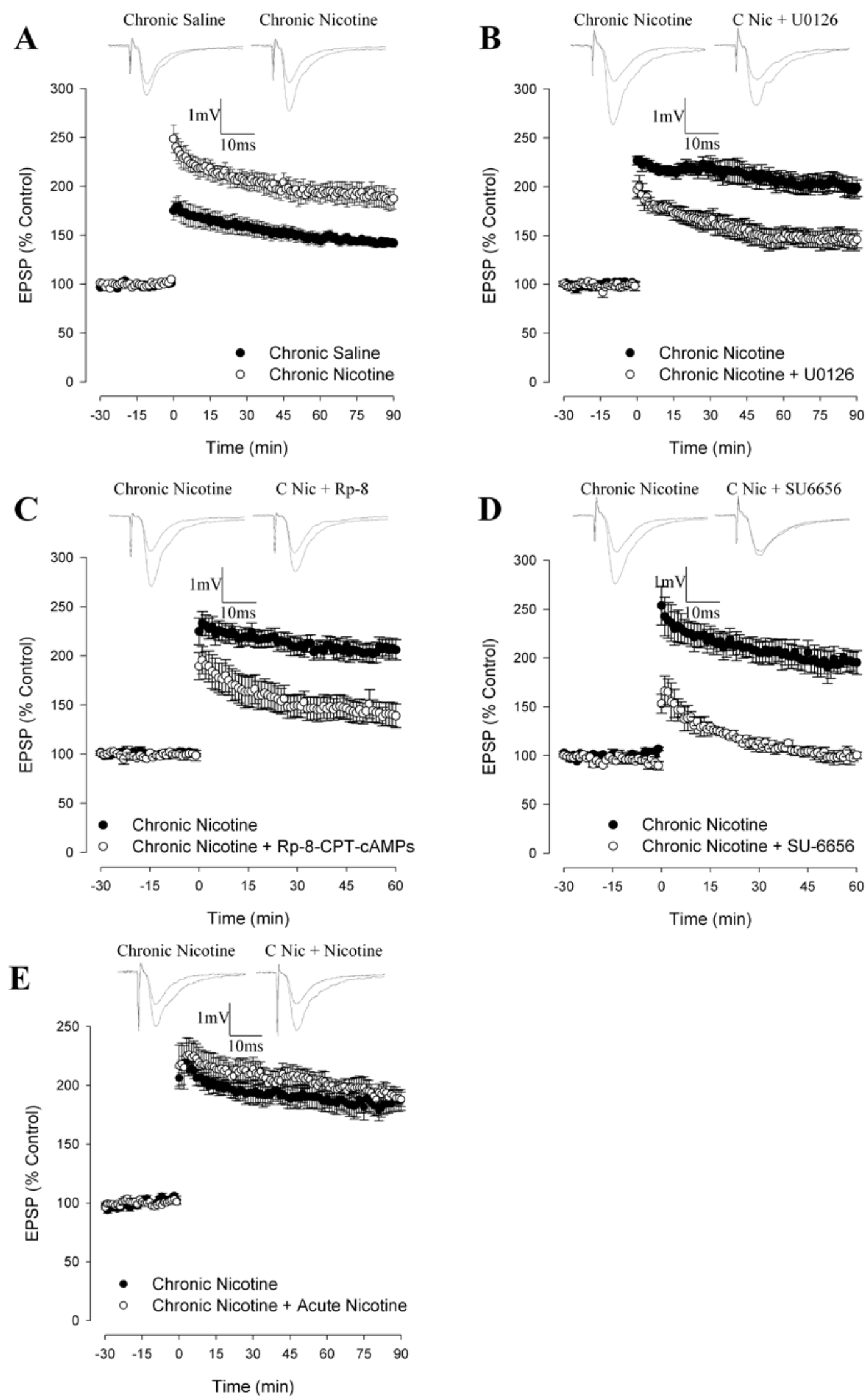


\section{Fig 5. PNU modulation of HFS induced LTP in the presence of nicotine in rat}

dentate gyrus. A, Acute application of the $\alpha 7 \mathrm{nAChR}$ positive allosteric modulator PNU-120596 $(1 \mu \mathrm{M})$ did not significantly effect LTP (open circles) when compared with control (closed circles). B, PNU-120596 also did not significantly affect nicotine $(5 \mu \mathrm{M})$ enhanced HFS-LTP (open circles) when compared with nicotine treatment alone (closed circles). C, The bar graph summarises the affects on HFS-LTP of a range of nicotine concentrations. Only $5 \mu \mathrm{M}$ nicotine significantly enhanced LTP when compared with control. 500nM and $100 \mathrm{nM}$ were sub enhancing concentrations of nicotine. D, LTP in the presence of both acute PNU-120596 and 500nM nicotine (open circles) is significantly enhanced when compared with 500nM nicotine alone (closed circles). E, The $\alpha 7$ nAChR selective antagonist MLA (50nM) (open circles) did not alter LTP when compared with control (closed circles). F, MLA does not significantly affect LTP in the presence of nicotine $(500 \mathrm{nM})$ (closed circles) when compared with control (not shown). In the presence of MLA (50nM), the combination of PNU and 500nM nicotine (open circles) no longer significantly enhanced LTP when compared with control (not shown). Traces illustrate EPSP’s before and 60min after HFS. 

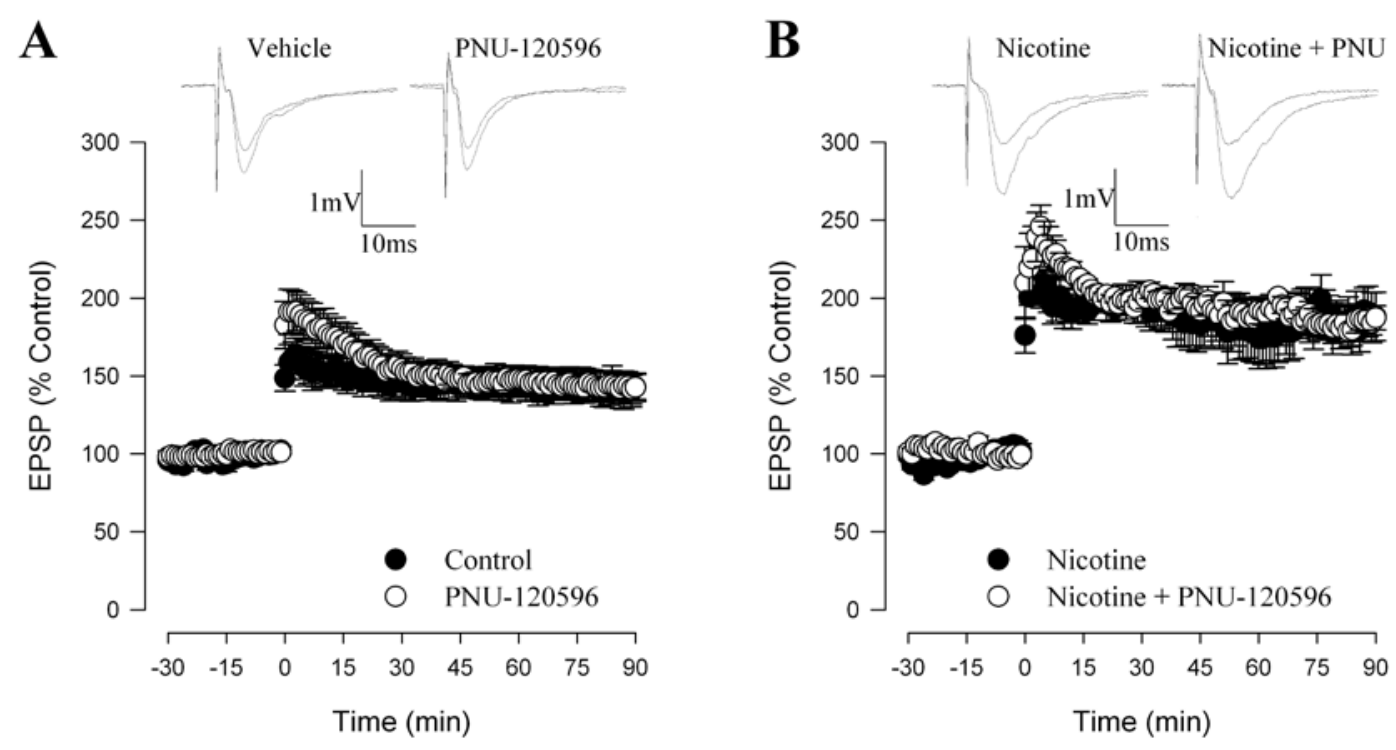

C
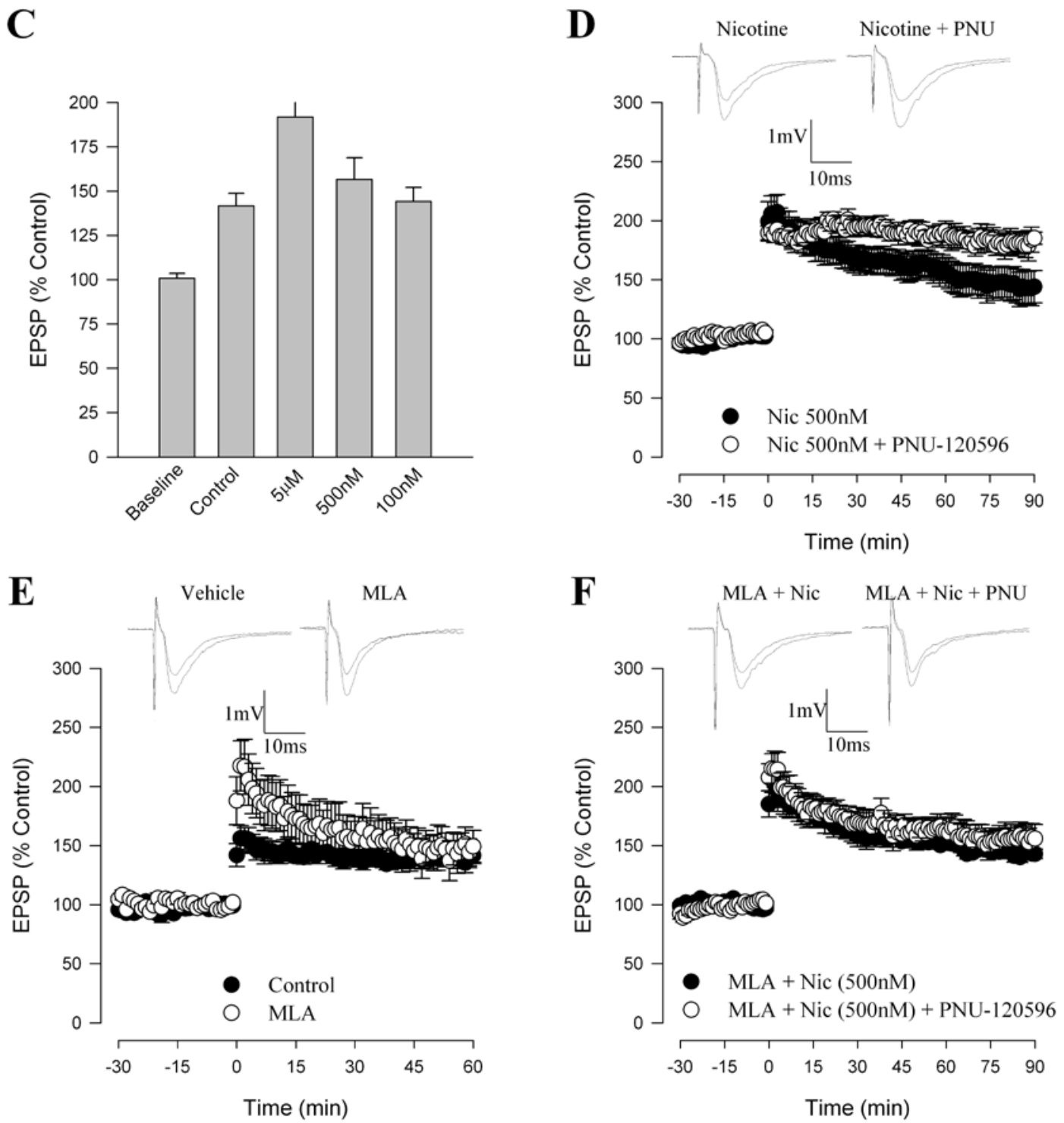
Fig 6. Inhibition of AChE results in enhanced HFS-LTP in the rat dentate gyrus. A, LTP is unaffected by $1 \mu \mathrm{M}$ physostigmine (closed circles), but is significantly enhanced in the presence of $10 \mu \mathrm{M}$ physostigmine (open circles). B, The AChE inhibitor, tacrine $(10 \mu \mathrm{M})$, enhanced HFS-LTP (open circles) when compared to control (closed circles). Traces illustrate EPSP's before and 60min after HFS. 

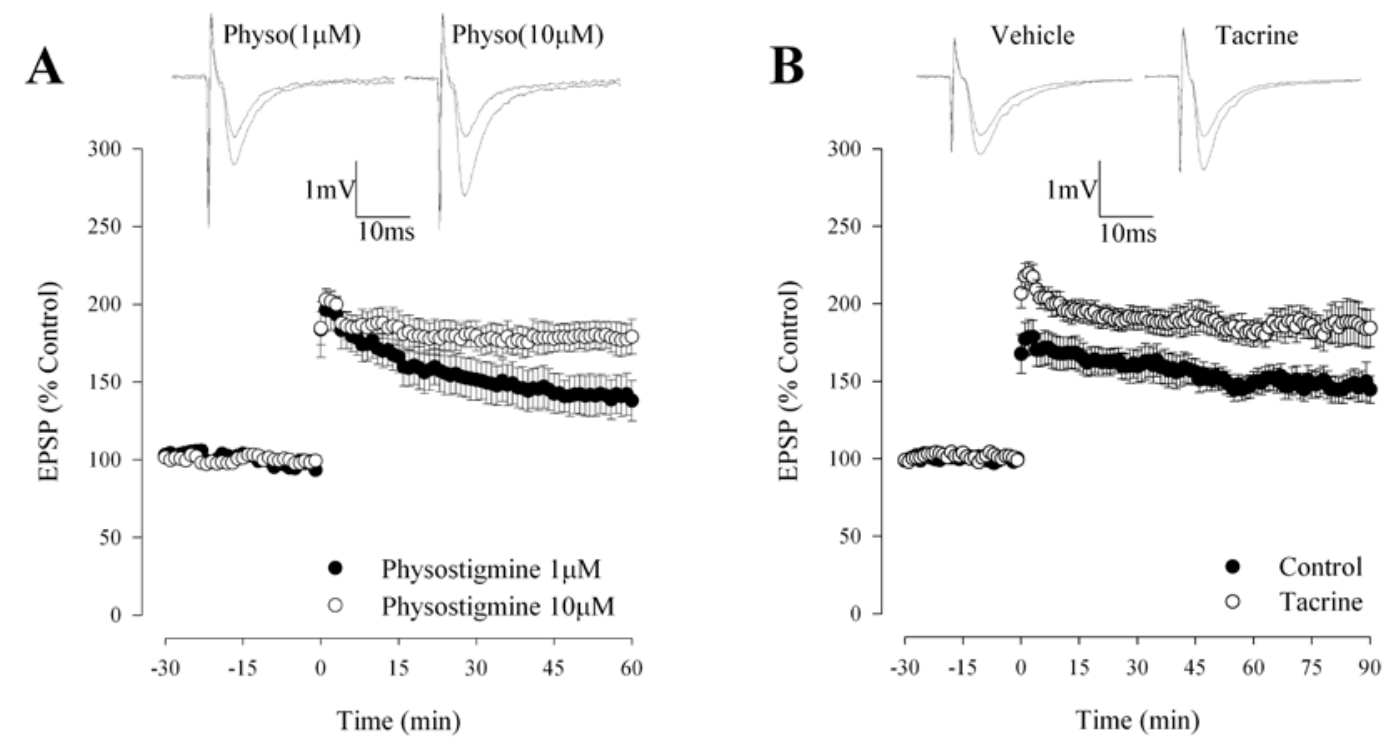
